\title{
Menores conectados y riesgos online: contenidos inadecuados, uso inapropiado de la información y uso excesivo de internet
}

\author{
Connected minors and online risks: inappropriate \\ content, inappropriate use of information, and \\ excessive use of the internet
}

\author{
Carmelo Garitaonandia; Inaki Karrera-Xuarros; Estefanía Jiménez-Iglesias; Nekane \\ Larrañaga
}

Cómo citar este artículo:

Garitaonandia, Carmelo; Karrera-Xuarros, Inaki; Jiménez-Iglesias, Estefanía; Larrañaga, Nekane (2020). “Menores conectados y riesgos online: contenidos inadecuados, uso inapropiado de la información y uso excesivo de internet". Profesional de la información, v. 29, n. 4, e290436.

https://doi.org/10.3145/epi.2020.jul.36

Artículo recibido el 13-11-2019

Aceptación definitiva: 03-03-2020
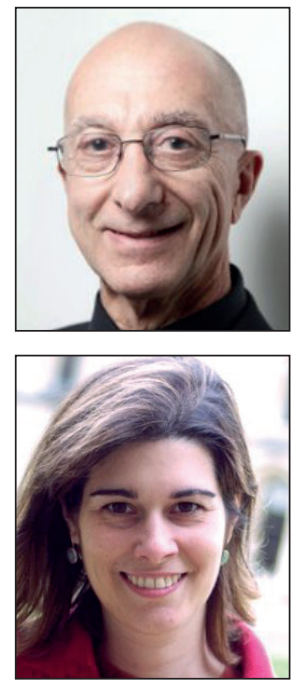

Carmelo Garitaonandia https://orcid.org/0000-0003-1662-4566

Universidad del País Vasco / Euskal Herriko Unibertsitatea

Fac. de Ciencias Sociales y de la Comunic. Campus Universitario Sarriena, $\mathrm{s} / \mathrm{n}$ 48940 Leioa (Bizkaia), España carmelo.garitaonandia@ehu.es

\section{Estefanía Jiménez-Iglesias} https://orcid.org/0000-0002-8689-8485

Universidad del País Vasco / Euskal Herriko Unibertsitatea

Fac. de Ciencias Sociales y de la Comunic. Campus Universitario Sarriena, $\mathrm{s} / \mathrm{n}$ 48940 Leioa (Bizkaia), España estefania.jimenez@ehu.eus

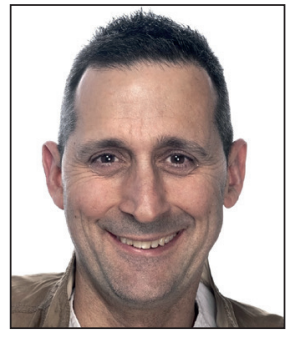

Inaki Karrera-Xuarros $\triangle$

https://orcid.org/0000-0003-4448-7749

Universidad del País Vasco / Euskal Herriko Unibertsitatea

Fac. de Ciencias Sociales y de la Comunic. Campus Universitario Sarriena, $\mathrm{s} / \mathrm{n}$ 48940 Leioa (Bizkaia), España

inaki.karrera@ehu.eus

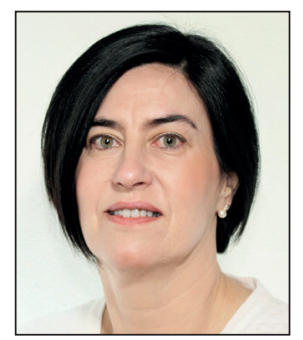

Nekane Larrañaga https://orcid.org/0000-0002-8062-3544

Universidad del País Vasco / Euskal Herriko Unibertsitatea

Fac. de Ciencias Sociales y de la Comunic. Campus Universitario Sarriena, $\mathrm{s} / \mathrm{n}$ 48940 Leioa (Bizkaia), España nekane.larranaga@ehu.eus

\section{Resumen}

Se presenta parte de los resultados más relevantes de una encuesta realizada a 2.900 menores españoles de entre 9 y 17 años usuarios de internet a quienes se preguntó sobre sus hábitos de navegación online. Se centra en el análisis de su exposición a contenidos inadecuados en internet, tipificados como información sobre formas de lesionar o autolesionarse, formas de suicidarse, anorexia, bulimia, mensajes de odio, consumo de drogas o imágenes violentas. También se analiza la exposición a experiencias con virus o malware y fraudes online, y riesgos relacionados con el mal uso de la información personal, el sharenting y el uso excesivo. Se advierten diferencias por franjas de edad, y también de género, por ejemplo, respecto a la exposición a mensajes de odio dirigidos contra ciertos grupos, que es notablemente más frecuente entre las adolescentes que entre los adolescentes. Los resultados, que son parcialmente comparables con los de sendas encuestas equivalentes realizadas en 2010 y 2015, permiten concluir que la exposición a los riesgos online se ha incrementado en los últimos años. 


\title{
Palabras clave
}

Adolescencia; Contenidos inadecuados; Problemas psicológicos; Discurso del odio; Internet; Infancia; Riesgos; Sharenting; Uso excesivo.

\begin{abstract}
This article presents some of the most relevant results of a survey of 2,900 Spanish minors aged between 9 and 17 years who are Internet users and who were asked about their online habits. It focuses on an analysis of their exposure to inappropriate content on the Internet, typified as information about injury to others or self-injury, ways to commit suicide, anorexia, bulimia, hate messages, drug use, or violent images. It also analyzes the exposure to experiences with viruses or malware and online fraud, and risks related to the misuse of personal information, sharenting, and excessive use. Differences are observed by age groups, and also by gender, for example, regarding the exposure to hate messages against certain groups, which during adolescence is noticeably more frequent among girls than among boys. The results, which are partially comparable to those of two equivalent surveys carried out in 2010 and 2015, allow us to conclude that the exposure to online risks has increased in recent years.
\end{abstract}

\section{Keywords}

Adolescence; Children; Excessive use; Inappropriate content; Internet; Harmful content; Hate speech; Psychological problems; Sharenting.

\section{Introducción y marco teórico}

Tanto los niños como los adolescentes están creciendo en un ecosistema de convergencia mediática (Livingstone; Haddon, 2009; Ito et al., 2009) caracterizado por una hibridación entre los medios móviles e internet, así como la creciente integración de los entornos online y presenciales en la vida cotidiana. La experiencia digital se ha acentuado con el uso de smartphones y tabletas, así como con los smartwatches, las aplicaciones que monitorizan la actividad física y otros recursos digitales que forman parte de internet de las cosas (Mascheroni; Holloway, 2019). Los nuevos servicios y aplicaciones van surgiendo a un ritmo acelerado. Los menores, y cada vez en edades más jóvenes, crecen en un sistema en el que es habitual el uso de las tecnologías de la información y la comunicación. De hecho, en España por término medio empiezan a usar los móviles a partir de los 7 años (Garmendia et al., 2016).

Internet, las redes sociales y los dispositivos móviles son parte integrante de la vida cotidiana de niños y adolescentes españoles (Garmendia et al., 2018). Estas tecnologías y plataformas les proporcionan recursos para el aprendizaje, la creatividad y la participación, pero también plantean retos para niños y jóvenes, progenitores, profesores y para todos aquellos profesionales que velan por la seguridad y el bienestar de los menores.
La experiencia digital de los menores se ha acentuado con el uso de smartphones, tabletas, smartwatches, aplicaciones que monitorizan la actividad física y otros recursos digitales de internet de las cosas

La evaluación de los beneficios y los riesgos de las actividades digitales depende de muchos factores. La investigación de la red EU kids online ha evidenciado que las oportunidades y los riesgos online van de la mano: cuanto más usan internet los menores, más se benefician de sus oportunidades y adquieren más competencias, pero se exponen a más riesgos (Livingstone et al., 2011; Mascheroni; Ólafsson, 2014). La exposición a los riesgos no ocasiona necesariamente daño: para muchos menores, tal y como ocurre con los riesgos de la vida normal, el contacto online con contenidos o situaciones de comunicación arriesgada puede desarrollar su resiliencia frente a los riesgos. Esto se traduce en una mayor capacidad para afrontar y gestionar situaciones de peligro.

Internet ha permitido la circulación sin precedentes de una inmensa cantidad de contenidos generados por los propios usuarios, contenidos que no son producidos ni distribuidos masivamente por medios ni empresas tecnológicas, sino que son realizados por personas particulares (user generated content). Las redes sociales son un medio importante para la interacción social, especialmente entre los adolescentes, siendo Instagram la plataforma más popular en este grupo de edad en EUA y la segunda en Alemania, después de YouTube (Guimarães, 2014). Si bien es cierto que la creación y la posibilidad de compartir contenidos constituyen unas de las oportunidades fundamentales que ofrece hoy internet y un elemento muy importante dentro de los procesos de alfabetización digital, hay ciertos contenidos generados por usuarios que son problemáticos:

- los que promueven desórdenes alimenticios (anorexia y bulimia),

- comportamientos autolesivos,

- consumo de drogas, o la

- discriminación y violencia contra ciertos grupos sociales, por motivos étnicos, religiosos, o de otra índole.

El discurso del odio expresa discriminación, intimidación, desaprobación, antagonismo y/o actitudes de prejuicio hacia características relacionadas con el sexo, la raza, la religión, la etnia, el color, el origen nacional, una discapacidad u orien- 
tación sexual. Está orientado a herir, deshumanizar, acosar, degradar y/o victimizar a determinados grupos y fomentar la insensibilidad y brutalidad hacia ellos (Cohen-Almagor, 2011).

En el caso de trastornos de la alimentación, según una encuesta realizada a principios de la década en 25 países europeos, el 10\% de los niños de 9 a 16 años había visto webs con esos contenidos inadecuados, y las niñas estaban más expuestas a este material que los niños (Livingstone et al., 2011). No obstante y a pesar de que el contenido pro-anorexia se ha extendido en YouTube, los videos que promocionan la ayuda contra la anorexia y se oponen a la comunidad pro-anorexia son más populares, y obtienen un feedback y comentarios más positivos que los videos pro-anorexia. El contenido anti-pro-anorexia ha sabido proporcionar una fuerza contraria generada por el usuario contra el contenido pro-anorexia en YouTube (Oksanen et al., 2015).

En relación con las autolesiones, y en el mismo sentido que las webs de trastornos alimentarios, la mayoría de quienes declararon su género en relación con la subida de fotos de autolesiones en Instagram eran mujeres -alrededor del 90\%-. Esto está en línea con estudios anteriores, que mostraban más chicas participando en autolesiones, y especialmente hiriendo su propio cuerpo (Bresin; Schoenleber, 2015). Además se da una asociación entre el aumento del número de comentarios y la creciente gravedad de esas heridas (Brown et al., 2018).

Hasta ahora se sabe muy poco sobre el discurso del odio online entre adolescentes y también se desconoce cómo la desinhibición en la Red influye en la relación entre ser espectadores y ser perpetradores del odio online (Wachs; Wright, 2018). Cohen-Almagor (2018), después de varios artículos desde 2009, hace un estudio pormenorizado del problema de los discursos del odio desde los primeros días de internet hasta la actualidad, refiriéndose en particular a las formas en las que los grupos racistas utilizan las redes, sus contenidos y sus propósitos. En relación con el discurso del odio, un sector particularmente vulnerable en España es el de los niños y adolescentes emigrantes, y en mayor medida los de origen magrebí. Su origen étnico o migratorio se utiliza contra ellos.

"Suben fotos manipuladas (a Instagram y Facebook) y ponen frases como vete a casa o puta mora. Esas son normalmente las palabras clave (chica, 17, Magreb)" (Casado et al., 2019, p. 61).

Aunque hay evidencias de que la exposición a este tipo de mensajes es relativamente común entre los menores (Livingstone et al., 2011), estas cuestiones han recibido menos atención por parte de la sociedad, de los legisladores e investigadores que otras, como el ciberbullying, el sexting, la pornografía o el contacto con extraños, online y en persona. En todo caso, según establece el informe del Parlamento Británico Disinformation and "Fake news": Final report:

"Las compañías de las redes sociales no pueden esconderse detrás de la afirmación de ser simplemente una plataforma y mantener que no tienen ninguna responsabilidad en la regulación del contenido de sus sitios web..., las empresas de tecnología (deberían) asumir la responsabilidad legal por el contenido identificado como perjudicial después de que haya sido publicado por los usuarios (House of Commons, 2019, p. 89).

\section{Metodología}

En el bienio 2017-2018 EU kids online llevó a cabo una encuesta en varios países europeos. Anteriormente se habían realizado dos encuestas similares en los domicilios de los menores:

- en 2010, EU kids online encuestó a 25.142 niños y niñas de entre 9 y 16 años y a sus progenitores en 25 países europeos, incluida España ${ }^{1}$ (Livingstone et al., 2011; Garmendia et al., 2011);

- entre 2013 y 2015 se realizó una nueva investigación, Net children go mobile, más centrada en el uso de dispositivos móviles: smartphones y tabletas, en ocho países, Bélgica, Dinamarca, Irlanda, Italia, Portugal, Reino Unido, Rumanía y España. El trabajo de campo cuantitativo en España se llevó a cabo en 2015², y los resultados se mostraron en un informe específico (Garmendia et al., 2016).

Para el estudio que presentamos en este artículo, el cuestionario se administró en centros escolares públicos y concertados a una muestra representativa de 2.900 niños y niñas de 9 a 17 años. A estos centros se desplazó un entrevistador que permaneció en el aula mientras los entrevistados respondían al cuestionario. Para garantizar la representatividad a nivel nacional, elegimos varias zonas: Madrid, Cataluña, Andalucía, Comunidad Valenciana, Galicia, País Vasco y Extremadura. Se eligieron 10 centros escolares en cada comunidad autónoma, menos en Extremadura (9). En Educación Primaria el 77,84\% fueron públicos y $22,16 \%$ concertados, y en Educación Secundaria el $60,37 \%$ públicos y 39,63\% concertados, reflejando la distribución de la población escolar española en función de la titularidad de su centro escolar. Se dividió la muestra a realizar en $80 \%$ centros ubicados en capitales y $20 \%$ en municipios más pequeños. En total, el cuestionario se mostró en 138 aulas, dos aulas de diferentes cursos por cada centro. El nivel de confianza es del 95,5\% y el error muestral es $+/-1,87$.

Los resultados de la encuesta, realizada entre octubre y diciembre de 2018, describen las características de los menores encuestados y su acceso a internet, los usos y actividades, oportunidades, la totalidad de los riesgos (bullying, contacto con desconocidos, mensajes e imágenes sexuales, y "otros riesgos"), y se han comparado con los resultados nacionales 
de la encuesta EU kids online 2010 (Livingstone et al., 2011; Garmendia et al., 2011) y de la encuesta Net children go mobile, de 2015 (Garmendia et al., 2016, Garmendia et al., 2018). La comparación permite ver cambios y continuidades en el uso de internet entre niños y adolescentes españoles (9 a 17 años) desde una perspectiva temporal. No obstante, la lectura de estos datos debe tener presentes ciertas diferencias metodológicas. En las encuestas de 2010 y 2015 la muestra abarcaba a niños y adolescentes de entre 9 y 16 años; en 2018 en cambio, la nuestra comprende también a los adolescentes de 17 años. El tamaño de la muestra utilizada ha variado: 1.000 menores (en 2010), 500 (en 2015) y 2.900 (en 2018). Las condiciones de administración de los cuestionarios también difieren: de la administración de los cuestionarios en los domicilios por un entrevistador en las encuestas de 2010 y 2015, a la auto-administración en 2018.

El objetivo genérico de este artículo es describir los resultados de exposición a los considerados en las encuestas "otros riesgos", que agrupan cuestiones de distinta naturaleza. Se distinguen los siguientes objetivos específicos:

- Describir los resultados de exposición a contenido considerado potencialmente dañino: formas de lesionar, autolesionarse o suicidarse, contenidos pro-anorexia o pro-bulimia, mensajes de odio contra ciertos grupos de personas, experiencias con drogas e imágenes violentas, relacionándolos con los resultados de 2010 y 2015;

- Describir la exposición a los riesgos online relacionados con el uso inapropiado de la información personal, y a riesgos comerciales y de seguridad de los dispositivos de acceso;

- Analizar los resultados relacionados con las prácticas de sharenting;

- Mostrar las autopercepciones de los encuestados respecto al tiempo que dedican a internet.

\section{Exposición a contenido potencialmente dañino}

En nuestro trabajo preguntamos a los menores:

"El año pasado ¿has visto contenido online o conversaciones donde las personas muestran alguno de estos temas?: hacerse daño o de herirse uno mismo, formas de suicidarse, maneras de estar muy delgado (anorexia, bulimia o delgadez extrema); mensajes de odio (por ejemplo, contra gentes de otras razas, religión, nacionalidad o sexualidad), consumo de drogas, imágenes gore (sangre o terror) o violentas" ${ }^{3}$.

La tabla 1 muestra con qué tipos de contenido problemático se han encontrado los menores, a cuáles de ellos el acceso es más frecuente, y el modo en el que esto varía con la edad y el género.

Tabla 1. Personas que han visto en el último año contenidos negativos generados por otros usuarios por edad (+11) y género (\%)

\begin{tabular}{|c|c|c|c|c|c|}
\hline \multirow{2}{*}{$\%$ que ha visto contenidos sobre... } & \multicolumn{2}{|c|}{ 11-13 años } & \multicolumn{2}{|c|}{ 14-17 años } & \multirow{2}{*}{ Tota } \\
\hline & Niño & Niña & Niño & Niña & \\
\hline Formas de hacerse daño o herirse uno mismo $(\mathrm{N}=2.153)$ & 17 & 19 & 29 & 45 & 26 \\
\hline Diferentes formas de suicidarse $(\mathrm{N}=2.158)$ & 12 & 12 & 20 & 33 & 18 \\
\hline $\begin{array}{l}\text { Maneras de estar muy delgado (que llevan a la anorexia, a la bulimia o la delgadez extrema) } \\
(\mathrm{N}=2.160)\end{array}$ & 11 & 15 & 18 & 37 & 19 \\
\hline $\begin{array}{l}\text { Mensajes de odio contra ciertos grupos de personas (gente de otras razas, religión, naciona- } \\
\text { lidad o sexualidad) }(\mathrm{N}=2.161)\end{array}$ & 23 & 25 & 45 & 59 & 36 \\
\hline Experiencias de tomar drogas $(\mathrm{N}=2.165)$ & 13 & 12 & 38 & 44 & 25 \\
\hline $\begin{array}{l}\text { Imágenes gore o violentas, por ejemplo, de personas que lastiman a otras personas o a } \\
\text { animales }(\mathrm{N}=2.158)\end{array}$ & 25 & 25 & 47 & 53 & 36 \\
\hline
\end{tabular}

EU kids online 2018 QF50a-f: El año pasado, ¿̇has visto contenido online o conversaciones donde las personas hablan o muestran alguno de estos temas? Opciones de respuesta: nunca; algunas veces; al menos una vez al mes; a diario o casi. Aunque la base general de la encuesta está compuesta por niños, niñas y adolescentes de $9-17$ años $(\mathrm{N}=2.900)$, estas cuestiones concretas sólo fueron planteadas a partir de los 11 años. En cada caso se especifica el número de respuestas que se obtuvo.

Los contenidos potencialmente dañinos con los que más contacto tienen los menores son claramente las imágenes gore o violentas y los mensajes de odio contra ciertos grupos de personas (de otras razas, religión, nacionalidad o sexualidad).

Es evidente que el contacto con contenidos inadecuados está estructurado por la edad: en la franja de 11 a 13 años tanto los chicos como las chicas tienen un acceso mucho más limitado que en la franja de 14 a 17. Cabe mencionar, por ejemplo, que entre los chicos más mayores el porcentaje que ha accedido a contenidos sobre experiencias con drogas triplica al que se da entre los más jóvenes. Así, las diferencias entre ambos grupos de edad resultan estadísticamente significativas en el visionado de todos los tipos de webs (Chi-cuadrado $p<, 001$ )

Analizando las diferencias entre género, y en lo que respecta al grupo de los menores de entre 11 y 13 años este tipo de webs son mucho menos visitadas y las diferencias entre niño o niña, no son estadísticamente significativas (Chi-cuadrado de Pearson n.s., no significativo).

En cambio, entre los adolescentes de 14-17 años, crece el porcentaje de visitas a este tipo de páginas y además se observan diferencias por género, siendo las chicas las que más las visionan. Estas diferencias son estadísticamente significativas, en el caso de webs sobre formas de hacerse daño o herirse uno mismo más entre las chicas, (Chi-cuadrado p<,005) o en las maneras 
de estar muy delgada, que llevan a la anorexia, a la bulimia o la delgadez extrema $(p<, 001)$, con más casos también entre las chicas.

Atendiendo a la comparación entre los datos actuales con los de 2010 y 2015, el acceso a contenidos inadecuados se ha visto incrementado en todas las categorías establecidas. Es probable que haya influido en alguna medida que la encuesta a los adolescentes en 2018 se haya extendido hasta los 17 años, mientras que, como se ha indicado, en las dos anteriores sólo se contemplaban los chicos y chicas de hasta 16 años, y a medida que cumplen años, es mayor la probabilidad de que contacten con contenidos de este tipo. Como se comprueba en el gráfico 1 , los incrementos más llamativos se refieren al avance del discurso del odio en forma de ataques a diferentes colectivos ( $20 \%$ más sobre la encuesta de 2015 hasta alcanzar un porcentaje del $36 \%$ ), y el consumo de drogas (16\% más hasta alcanzar el $25 \%)$. A su vez, el porcentaje de visitas a las páginas en las que se habla sobre formas de suicidarse, que en 2010 era del 5\% y en 2015 alcanzaba el 10\%, se ha elevado de una forma notable: en 2018 llega al 18\%. No hay registros respecto al contacto con imágenes violentas en 2010 y 2015 con los que poder establecer comparación.

\section{Uso inapropiado de datos personales, riesgos comerciales y de seguridad de equipos}

En este apartado nos vamos a ocupar de otros riesgos que corren los menores:

- riesgos técnicos, como que se introduzca en el equipo o dispositivo un virus o software malintencionado (malware);

- pérdida de dinero como consecuencia de ser víctima de fraudes online;

- riesgos relacionados con el mal uso de la información personal.

En ocasiones las personas no saben que tan pronto como se conectan a internet revelan su identidad. Ese último riesgo comprende, entre otras cosas:

- ser víctima del pirateo (hacking) de la cuenta de correo electrónico o del perfil en las redes sociales;

- uso inadecuado de información personal y de fotos que un tercero se atribuye (por ejemplo, mediante la creación de perfiles falsos);

- existencia de personas que se hacen pasar por otras, o catfishing.

Lee (2018) encontró que el nivel de competencia informática de una persona era un predictor significativo de la piratería informática -accediendo, por ejemplo, a la cuenta de otra persona o a sus archivos a través de la detección de contraseñas-. Este resultado está respaldado por estudios previos que indican que la piratería requiere un alto nivel de conocimientos informáticos para penetrar en los sistemas informáticos mediante la explotación de vulnerabilidades o fallos de los sistemas operativos, como los que se ejecutan en un ordenador personal o teléfono móvil (Rogers; Smoak; Liu, 2006).

Mientras la bibliografía sobre estas cuestiones es aún dispersa, hay algunas evidencias de que el abuso y el mal uso de la información personal merecen atención. En el estudio realizado por Soldatova y Rasskazova (2016) en once regiones de Rusia, se concluye que los riesgos más comunes de los menores en la Red fueron acceder a contenidos sexuales y dañinos, ser víctima del fraude y el robo de información personal, así como los encuentros personales con quienes habían conocido online.

Tabla 2. Otras experiencias negativas por edad y género (\%)

\begin{tabular}{|c|c|c|c|c|c|}
\hline \multirow{2}{*}{$\begin{array}{l}\% \text { que ha visto contenidos sobre... } \\
\mathrm{N}=2.900\end{array}$} & \multicolumn{2}{|c|}{ 9-12 años } & \multicolumn{2}{|c|}{ 13-17 años } & \multirow{2}{*}{ Total } \\
\hline & Niño & Niña & Niño & Niña & \\
\hline Alguien usó mi información personal de una manera que no me gustó & 5 & 5 & 9 & 12 & 7 \\
\hline Al dispositivo que uso (móvil, tableta u ordenador) le entró un virus o un programa espía. & 16 & 12 & 15 & 16 & 15 \\
\hline Perdí dinero al ser engañado en internet & 3 & 1 & 3 & 3 & 2 \\
\hline Alguien usó mi contraseña para acceder a mi información o fingir que era yo & 7 & 6 & 10 & 12 & 8 \\
\hline Alguien creó una página o imagen sobre mí que era negativa o hiriente & 2 & 2 & 2 & 4 & 2 \\
\hline Gasté demasiado dinero en compras con aplicaciones o en juegos online & 10 & 2 & 15 & 3 & 8 \\
\hline Alguien descubrió dónde estaba porque rastreó mi teléfono o dispositivo & 3 & 2 & 3 & 4 & 3 \\
\hline
\end{tabular}

EU kids online 2018 QF60 a-g: El año pasado, ¿te ha sucedido alguna de las siguientes cosas en internet? Opciones: No; Sí; No sé. Base: Niños, niñas y adolescentes de $9-17$ años $(N=2.900)$. 
Los virus y los programas espía (spyware) constituyen el riesgo técnico con el que más frecuentemente se encuentran los menores en 2018 , y alcanza al $15 \%$, con escasas diferencias por edad y género (tabla 2). Este riesgo ha disminuido desde 2015, ya que entonces se había enfrentado a él uno de cada cuatro encuestados (Garmendia et al., 2016).
Los virus y los programas espía (spyware) constituyen el riesgo técnico con el que más frecuentemente se encuentran los menores, con escasas diferencias por edad y género

Se aprecian diferencias entre la incidencia de estos riesgos entre las dos franjas de edad: a más edad, mayor porcentaje. Las diferencias por edad resultan significativas (Chi-cuadrado $p<, 001$ ) en estos tres casos:

- en el uso de información personal de una forma que no les gustó;

- en que alguien utilizó su contraseña para acceder a información personal;

- en el gasto de dinero en compras con aplicaciones o en juegos online.

En cualquier caso, y en términos generales, no hay muchas diferencias por razones de género, salvo en lo relativo a gastar dinero en compras con aplicaciones o en juegos online. Este riesgo se puede considerar abiertamente "masculino" en ambas franjas de edad: los niños de 9 a 12 años están $9 \%$ por encima de las chicas (10\% frente a $2 \%$ ), y en la franja de 13 a 17 años, los chicos $12 \%$ por encima de sus compañeras (15\% frente a 3\%). Sin embargo, estas diferencias de género observadas en ninguno de los casos han resultado ser estadísticamente significativas (Chi-cuadrado n.s.).

\section{Sharenting: padres, madres, tutores, amigos y/o profesorado compartiendo información sobre menores}

A menudo la vida digital de los niños y los jóvenes comienza incluso antes de iniciarse en el uso de internet; incluso antes del nacimiento, con la difusión de imágenes de las ecografías, que constituye una práctica cada vez más común durante el embarazo (Leaver, 2017). Se denomina sharenting a realizar en las redes sociales comentarios sobre situaciones divertidas de las vidas de los menores y/o compartir imágenes y vídeos por parte de sus padres. Este anglicismo proviene de la combinación de los términos share (compartir) y parenting (parentalidad). Los rastros digitales, sobre los que los protagonistas no tienen control, se quedan en la Red y se convierten en parte importante de su identidad digital. Además de ser una violación de su privacidad, estas prácticas contribuyen a una creciente vigilancia digital (Mascheroni; Holloway, 2019). Por ello, se empieza a constatar el riesgo detrás de este hábito y en consecuencia, a actuar con mayor cautela a la hora de elegir qué compartir online (Blum-Ross; Livingstone, 2017). Sin embargo, el sharenting ha aumentado (tabla 3).

Tabla 3. Prácticas de riesgo por edad y género (\%)

\begin{tabular}{|c|c|c|c|c|c|}
\hline \multirow{2}{*}{$\begin{array}{l}\text { \% de los que responden "A menudo" o "Muy a menudo" } \\
\mathrm{N}=2.900\end{array}$} & \multicolumn{2}{|c|}{ 9-12 años } & \multicolumn{2}{|c|}{ 13-17 años } & \multirow{2}{*}{ Total } \\
\hline & Niño & Niña & Niño & Niña & \\
\hline $\begin{array}{l}\text { Mi padre/madre/cuidador publicó en internet información sobre mí (mensajes, imágenes o } \\
\text { películas) sin preguntarme primero si estaba de acuerdo }\end{array}$ & 12 & 9 & 23 & 28 & 17 \\
\hline $\begin{array}{l}\text { Recibí comentarios negativos o hirientes de alguna persona por algo que mi padre/madre/cui- } \\
\text { dador publicó online }\end{array}$ & 5 & 2 & 4 & 4 & 4 \\
\hline Le pedí a mi padre/madre/cuidador que eliminara cosas que había publicado en internet & 10 & 7 & 11 & 21 & 12 \\
\hline Estaba molesto por la información que mis padres publicaron online & 8 & 4 & 10 & 13 & 8 \\
\hline $\begin{array}{l}\text { Mi(s) profesor(es) publicaron en internet información sobre mí sin preguntarme primero si } \\
\text { estaba de acuerdo }\end{array}$ & 4 & 3 & 6 & 4 & 4 \\
\hline $\begin{array}{l}\text { Mi(s) amigo(s) publicaron en internet información sobre mí sin preguntarme primero si estaba } \\
\text { de acuerdo }\end{array}$ & 9 & 12 & 30 & 43 & 22 \\
\hline
\end{tabular}

EU kids online 2018 QF80: El año pasado, ¿con qué frecuencia te ha pasado alguna de estas cosas? Base: Niños, niñas y adolescentes de 9-17 años ( $N=2.900)$.

El $17 \%$ de los niños y de las niñas encuestadas afirma que sus propios padres/madres y/o cuidadores publicaron mensajes, imágenes o vídeos sin preguntarles previamente si estaban de acuerdo. Probablemente este aumento esté relacionado con la sensibilidad de los propios menores ante las injerencias del mundo adulto en la gestión de su identidad digital.
Se denomina sharenting a realizar en las redes sociales comentarios sobre situaciones divertidas de las vidas de los menores y/o compartir imágenes y vídeos por parte de sus padres

Entre los chicos, de una franja de edad a la otra el porcentaje se duplica; entre las chicas, se triplica. Casi una de cada tres chicas de 13 a 17 años (28\%) señala que le ha ocurrido eso. El 12\% del total de encuestados solicitó a los padres y/o cuidadores que eliminaran cosas publicadas en internet, y de nuevo es en la franja de chicas de mayor edad donde el porcentaje se eleva con respecto a sus compañeros chicos y los chicos y chicas de menor edad. Sin embargo, estas diferencias por edad o sexo no son estadísticamente significativas (Chi-cuadrado n.s.). 
Un $8 \%$ sobre el conjunto se molestó por información que sus padres/madres publicaron en internet, y también aquí, las chicas mayores se sitúan por encima de la media (13\%). Afortunadamente las consecuencias negativas del sharenting no parecen ser frecuentes: un $4 \%$ de chicos y chicas de entre 13 a 17 años recibieron comentarios negativos o hirientes a consecuencia de alguna publicación online de ese tipo.
El $17 \%$ de los niños y niñas encuestados afirman que sus propios padres/madres y/o cuidadores publicaron mensajes, imágenes o vídeos sin preguntarles previamente si estaban de acuerdo

La difusión de imágenes por el profesorado sin pedir permiso tampoco parece ser una práctica común, o al menos sólo el $4 \%$ de los encuestados señala que eso sucediera. Por el contrario, que niños y niñas publiquen en internet información sobre sus amigos sin haberles pedido permiso previamente parece ser una práctica habitual: el $22 \%$ dicen que sus amigos difundieron información sobre ellos sin haberles preguntado antes si estaban de acuerdo. A este respecto se advierten notables diferencias por edad y sexo: el porcentaje se eleva al 43\% entre las chicas de 13 a 17 años. Aunque las diferencias de género no resultan ser estadísticamente significativas, sí son significativas las diferencias de edad (Chi-cuadrado $p<, 001$ ), dándose más casos entre los mayores o adolescentes.

\section{Uso excesivo de internet}

El temor de que los niños, las niñas y los jóvenes no consigan regular el uso que hacen de internet y pasen demasiado tiempo conectados es una preocupación en aumento entre padres, madres y tutores legales. Además, se ha convertido en un tema recurrente entre los llamados "media panics" o pánicos mediáticos. El problema parece haberse generalizado más aún con la popularización del smartphone (Mascheroni; Ólafsson, 2014), que siempre está al alcance de la mano, cada vez más integrado en nuestras actividades diarias y casi percibido como una extensión misma del cuerpo (Vincent; Fortunati, 2009).

Estar online y accesible a amistades y/o familiares se ha convertido en una parte importante de las expectativas que regulan las relaciones interpersonales, además de ofrecer cierto grado de seguridad personal. Así se genera una forma de apego o dependencia emocional, no tanto hacia el medio (internet) sino hacia las relaciones y contenidos que se transmiten (Mascheroni; Vincent, 2016).

El concepto de "adicción a internet" está en entredicho. Si bien en un primer momento este término fue incluido entre los trastornos de control de impulsos y asimilación junto con otras adicciones patológicas como los juegos de azar, estudios recientes adoptan el "modelo compensación" (Kardefelt-Winther, 2014), según el cual algunos individuos recurren al uso excesivo de internet para compensar ciertas dificultades psicológicas y/o como vía de escape a sus problemas. Por tanto, parece más adecuado la utilización de la expresión "uso excesivo" de internet al referirse a comportamientos que no son necesariamente indicadores de trastornos psicológicos (Smahel et al., 2012).

El 40\% de los menores afirma haberse sentido molesto alguna vez ("pocas veces al mes") al no estar en internet, y un $7 \%$ afirma que lo hace con frecuencia ("casi todas las semanas"). Un porcentaje parecido afirma usar internet aun sin estar realmente interesado ( $36 \%$ y $8 \%$, respectivamente), lo cual nos habla de políticas de navegación que en ocasiones son rutinarias, asentadas en la cotidianidad y en ocasiones sin objetivos claros de búsqueda de información o interés por compartir contenido.

El 33\% afirma que como consecuencia de sus hábitos online a veces ("pocas veces al mes") pasa menos tiempo con la familia y con los amigos y un $10 \%$ señala que esta situación tiene una frecuencia diaria o semanal. Igualmente, un $39 \%$ afirma haber intentado sin éxito pasar menos tiempo en internet: la mayoría de ellos, el $29 \%$ de los entrevistados, dicen pasar por esa situación "pocas veces al mes", pero hay un $10 \%$ que lo ha intentado "casi todas las semanas". Para un 5\% los conflictos con la familia y con los amigos a causa del uso excesivo de internet son frecuentes ("casi todas las semanas") y al $19 \%$ esto le sucede de manera ocasional. Aunque un $12 \%$ señala que se ha quedado sin comer o sin dormir por estar en internet (un 1\% "casi todas las semanas"), es interesante reseñar que los valores que señalan situaciones como el dejar de comer o dormir por navegar en

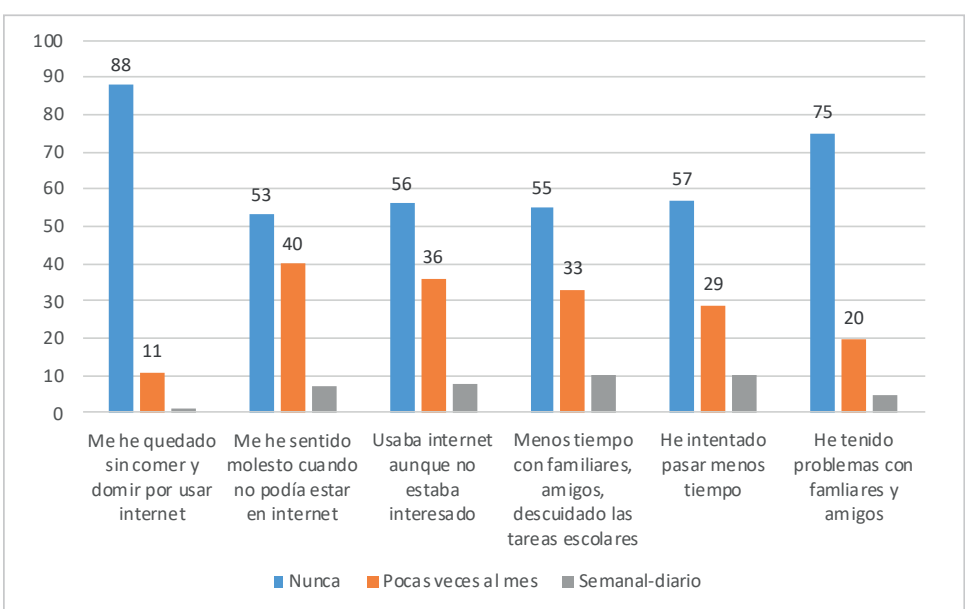

Gráfico 2. Percepciones sobre el uso excesivo de internet entre menores de 9 a 17 años (\%).

EU kids online 2018 QF70: El año pasado, ¿con qué frecuencia te han sucedido estas cosas?

Base: Niños, niñas y adolescentes de 9-17 años ( $N=2.900)$. 
internet han descendido notablemente en relación con los valores indicados en el informe de 2015 (Garmendia et al., 2016), pese al aumento en el tiempo y las posibilidades de acceso que se han producido en ese período.

\section{Conclusiones y discusión}

Existe una creciente concienciación sobre los riesgos online entre padres y madres y menores, que se manifiesta en una mayor participación de los progenitores en la mediación de la seguridad de los menores online, y en el desarrollo de habilidades de seguridad o la adopción de medidas preventivas entre los menores (Garmendia et al., 2016). La exposición a los riesgos online se ha incrementado en los últimos años, especialmente entre los menores que utilizan dispositivos móviles para navegar. La máxima de "más oportunidades, más riesgos" sigue constituyendo un marco válido para entender los cambios relacionados con los smartphones y las tabletas, cambios que conducen a un internet más ubicuo y omnipresente en el día a día de los menores.

Sabemos que las actividades diarias más frecuentes que realizan en, con, o gracias a internet los menores son las de comunicación con la familia y los pares, las de entretenimiento (música, videos y juego online) y la de realizar las tareas escolares. Es difícil definir estas actividades online como totalmente beneficiosas o arriesgadas. También sabemos que los niños que llevan a cabo una gama más amplia de actividades se exponen a más riesgos, pero también están mejor preparados para afrontarlos, por lo que sufren menos daño (Livingstone; Hasebrink; Görzig, 2012). Dado que aumenta el porcentaje de niños internautas, desde más temprana edad, y que lo son desde más aparatos y en contextos más variados, no resulta sorprendente que la exposición a riesgos online también aumente. Es necesario resaltar que el incremento de aquellos que han sufrido daños como resultado de experiencias de riesgo no ha aumentado en la misma proporción.

Las webs de contenido dañino más visitadas por los menores son claramente las que contienen mensajes de odio contra ciertos grupos de personas (de otras razas, religión, nacionalidad u orientación sexual) y las que muestran imágenes gore o violentas. Como se ha visto, más de un tercio de los menores las han visitado y, en particular, los de más edad, con diferencias notables en función del género.

La mayoría de las experiencias online no tienen por qué ser dañinas, y de hecho los menores no las perciben como peligrosas o problemáticas (Livingstone; Hasebrink; Görzig, 2012; Vandoninck; D’Haenens; Roe, 2013). Sin embargo, cuando se encuentran con experiencias negativas en internet, los menores despliegan una serie de estrategias para adaptarse a la situación y reducir el estrés emocional y psicológico derivado de la situación. Afrontar riesgos online implica para los menores adoptar "estrategias de resolución de problemas específicos de internet" tras una experiencia online negativa (Vandoninck; D’Haenens; Roe, 2013, p. 61). La encuesta EU kids online (Livingstone et al., 2011) identificaba tres tipos de estrategias para afrontar los riesgos:

- respuestas pasivas, que incluyen actitudes resignadas (dejar de utilizar internet durante un tiempo) y autoacusatorias (sentirse culpable por lo que ha ocurrido);

- respuestas proactivas: como reportar o denunciar contenidos o contactos inadecuados, bloquear a los contactos no deseados, etc.;

- respuestas comunicativas: hablar sobre lo sucedido con padres y madres, profesores u otros adultos de confianza.

Aprender cómo gestionar las experiencias negativas de una manera eficaz, así como detectar cuáles son las respuestas más adecuadas y efectivas para cada ocasión, forma parte del proceso de construcción de resiliencia (Vandoninck; D’Haenens; Roe, 2013; Vandoninck; D’Haenens, 2018) y de adaptación al entorno.

La estrategia para afrontar los riesgos online más habitualmente adaptada por los menores pasa por buscar apoyo en su entorno social, aunque en la mayoría de los casos tienden a combinar dos estrategias (Livingstone et al., 2011). La investigación previa ha probado que los menores que reciben un apoyo mayor por parte de sus pares son más resistentes a las experiencias negativas en internet, y que tanto los padres como el profesorado están en la posición de mediar en la construcción de resiliencia online si activamente se implican en las actividades online y de seguridad en internet de las que participan los niños (Vandoninck; D’Haenens; Roe, 2013). La importancia de padres y madres como fuente primaria de apoyo en caso de experiencias desagradables disminuye con la edad, y particularmente entre los chicos. Paralelamente, los adolescentes son más propensos que los niños más pequeños a recurrir a sus pares para buscar apoyo.

La mediación de la familia debe ser fundamental para prevenir y gestionar los riesgos en internet y los usos inadecuados. En casi todos los grupos observados se han detectado carencias en esa área, y en muchas ocasiones se debe a una deficiente alfabetización digital de los progenitores. En cualquier caso, y a pesar de que los menores son más conscientes de los peligros asociados a internet y a situaciones potencialmente conflictivas, sigue siendo necesario promover usos de la comunicación móvil más seguros y responsables. Esto podría pasar por incrementar la conciencia sobre las cuestiones 
relacionadas con la privacidad, las aplicaciones diseñadas para denunciar o bloquear, las funciones vinculadas al control y la geolocalización o los riesgos asociados a la escalada de intercambios que a veces se dan en casos de conflictos online (Marwick; Boyd, 2014).

\section{Notas}

1. La investigación fue financiada por el Safer Internet Programme (ahora Better Internet for Kids, BIK) de la Comisión Europea. En el caso español fue financiada a través de los proyectos IT961-16 del Gobierno Vasco y CSO2017-88431-R del Mineco.

2. Financiado a través del proyecto CSO2013-47304-R del Mineco.

3. Por razones éticas, esta pregunta no se dirigió a los niños y a las niñas de 9 y 10 años.

\section{Referencias}

Blum-Ross, Alicia; Livingstone, Sonia (2017). "Sharenting', parent blogging and the boundaries of the digital self". Popular communication, v. 15, n. 2, pp. 110-125.

https://doi.org/10.1080/15405702.2016.1223300

Bresin, Konrad; Schoenleber, Michelle (2015). "Gender differences in the prevalence of nonsuicidal self-injury: a meta-analysis". Clinical psychology review, v. 38, pp. 55-64.

https://doi.org/10.1016/j.cpr.2015.02.009

Brown, Rebecca C.; Fischer, Tony; Goldwich, A. David; Keller, Ferdinand; Young, Robert; Plener, Paul L. (2018). “\#cutting: Non-suicidal self-injury (NSSI) on Instagram". Psychological medicine, v. 48, n. 2, pp. 337-346.

https://doi.org/10.1017/S0033291717001751

Casado, Miguel-Ángel; Garitaonandia, Carmelo; Moreno, Gorka; Jiménez-Iglesias, Estefanía (2019). “Immigrant children and the internet in Spain: Uses, opportunities, and risks". Media and communication, v. 7, n. 1, pp. 56-65. https://doi.org/10.17645/mac.v7i1.1478

Cohen-Almagor, Raphael (2011). Fighting hate and bigotry on the Internet. Policy and internet, v. 3, n. 3, pp. 1-26. https://doi.org/10.2202/1944-2866.1059

Cohen-Almagor, Raphael (2018). "When a ritual murder occurred at Purim. The harm in hate speech". El profesional de la información, v. 27, n. 3, pp. 671-681.

https://doi.org/10.3145/epi.2018.may.20

Garmendia, Maialen; Casado, Miguel-Ángel; Jiménez-Iglesias, Estefanía; Garitaonandia, Carmelo (2018). “Oportunidades, riesgos, daño y habilidades digitales de los menores españoles”. En: Jiménez-Iglesias, Estefanía; Garmendia, Maialen; Casado, Miguel-Ángel (coords.). Entre selfies y whatsapps. Oportunidades y riesgos para la infancia y la adolescencia conectada. Barcelona: Ed. Gedisa. ISBN: 9788416919888

Garmendia, Maialen; Garitaonandia, Carmelo; Martínez, Gemma; Casado, Miguel-Ángel (2011). Riesgos y seguridad en Internet: los menores españoles en el contexto europeo. Bilbao: Universidad del País Vasco. ISBN: 9788498605204 https://www.observatoriodelainfancia.es/oia/esp/documentos_ficha. aspx?id=3155

Garmendia, Maialen; Jiménez-Iglesias, Estefanía; Casado, Miguel-Ángel; Garitaonandia, Carmelo; Mascheroni, Giovanna (2016). Net children go mobile: Riesgos y oportunidades en internet y uso de dispositivos móviles entre menores españoles (2010-2015). Bilbao: Universidad del País Vasco. ISBN: 9788867802883 https://netchildrengomobile.eu/ncgm/wp-content/uploads/2013/07/Net-Children-Go-Mobile-Spain.pdf

Guimarães, Thiago (2014). Revealed: the demographic trends for every social network. Business Insider. http://www.businessinsider.de/2014-social-media-demographics-update-2014-9?r=US\&IR=T

House of Commons (2019). Disinformation and "fake news": Final report. Digital Culture, Media and Sport Committee. https://writix.co.uk/wp-content/uploads/2022/03/digital-culture-media-and-sport-committee-fake-news-reportpublished-17-19.pdf

Ito, Mizuko; Baumer, Sonja; Bittanti, Matteo; Boyd, Danah; Cody, Rachel; Herr-Stephenson, Becky; Horst, Heather A.; Lange, Patricia G.; Mahendran, Dilan; Martínez, Katynka Z.; Pascoe, C. J.; Robinson, Laura; Sims, Christo; Tripp, Lisa (2009). Hanging out, messing around and geeking out: Kids living and learning with new media. Cambridge, MA: MIT Press. ISBN: 9780262258920

https://doi.org/10.7551/mitpress/8402.001.0001

Kardefelt-Whinther, Daniel (2014). "A conceptual and methodological critique of internet addiction research: Towards a model of compensatory internet use". Computers in human behavior, v. 31, pp. 351-354.

https://doi.org/10.1016/j.chb.2013.10.059 
Leaver, Tama (2017). "Intimate surveillance: Normalizing parental monitoring and mediation of infants online". Social media+ society, v. 3, n. 2.

https://doi.org/10.1177/2056305117707192

Lee, Byung H. (2018). "Explaining cyber deviance among school-aged youth". Child indicators research, v. 11, n. 1, pp. 563-584. https://doi.org/10.1007/s12187-017-9450-2

Livingstone, Sonia; Haddon, Leslie (eds.) (2009). Kids online. Opportunities and risks for children. Bristol: Policy Press. ISBN: 9781847424389

Livingstone, Sonia; Haddon, Leslie; Görzig, Anke; Ólafsson, Kjartan (2011). Risks and safety on the internet: The perspective of European children. Full findings and policy implications from the EU kids online survey of 9-16 years olds and their parents in 25 countries. London: LSE, EU kids online.

http://eprints.Ise.ac.uk/33731/1/Risks\%20and\%20safety\%20on\%20the\%20internet\%28/sero\%29.pdf

Livingstone, Sonia; Hasebrink, Uwe; Görzig, Anke (2012). "Towards a general model of determinants of risks and safety". In: Livingstone, Sonia; Haddon, Leslie; Görzig, Anke (eds.). Children, risk and safety on the internet: Research and policy challenges in comparative perspective. Bristol: Policy Press, pp. 323-337. ISBN: 9781847428820

https://core.ac.uk/reader/19578208

Marwick, Alice; Boyd, Danah (2014). “'It's just drama': teen perspectives on conflict and aggression in a networked era”. Journal of youth studies, v. 17, n. 9, pp. 1187-1204.

https://doi.org/10.1080/13676261.2014.901493

Mascheroni, Giovanna; Holloway, Donell (2019). "The quantified child: Discourses and practices of dataveillance in different life stages". In: Erstad, Ola; Flewitt, Rosie; Kümmerling-Meibauer, Bettina; Pires-Pereira, Íris S. (eds.). The Routledge handbook of digital literacies in early childhood. ISBN: 9780203730638

Mascheroni, Giovanna; Ólafsson, Kjartan (2014). Net children go mobile: Risks and opportunities. Milan: Educat. ISBN: 9788867802883

http://netchildrengomobile.eu/ncgm/wp-content/uploads/2013/07/DEF_NCGM_SecondEdition_Report.pdf

Mascheroni, Giovanna; Vincent, Jane (2016). "Perpetual contact as a communicative affordance: opportunities, constraints and emotions". Mobile media and communication, v. 4, n. 3, pp. 310-326.

https://doi.org/10.1177/2050157916639347

Oksanen, Atte; García, David; Sirola, Anu; Näsi, Matti; Kaakinen, Markus; Keipi, Teo; Räsänen, Pekka (2015). “Pro-anorexia and anti-pro-anorexia videos on YouTube: Sentiment analysis of user responses". Journal of medical internet research, v. 17, n. 11, e256.

https://doi.org/10.2196/jmir.5007

Rogers, Marc; Smoak, Natalie D.; Liu, Jia (2006). "Self-reported deviant computer behavior: a big-5, moral choice, and manipulative exploitive behavior analysis. Deviant behavior, v. 27, n. 3, pp. 245-268.

https://doi.org/10.1080/01639620600605333

Smahel, David; Helsper, Ellen; Green, Lelia; Kalmus, Veronika; Blinka, Lukas; Ólafsson, Kjartan (2012). Excessive internet use among European children. London: EU kids online.

https://www.researchgate.net/publication/261316716_Excessive_internet_use_among_European_children

Soldatova, Galina U.; Rasskazova, Elena I. (2016). "Adolescent safety on the internet: Risks, coping with problems and parental mediation". Russian education and society, v. 58, n. 2, pp. 133-162.

https://doi.org/10.1080/10609393.2016.1214492

Vandoninck, Sofie; D’Haenens, Leen (2018). "Resiliencia online: la capacidad de minimizar el impacto de los riesgos y de gestionar las situaciones potencialmente dañinas en Internet". En: Jiménez-Iglesias, Estefanía; Garmendia, Maialen; Casado, Miguel-Ángel (eds.). Entre selfies y whatsapps. Oportunidades y riesgos para la infancia y la adolescencia conectada. Barcelona: Gedisa, pp. 189-207. ISBN: 9788416919871

Vandoninck, Sofie; D’Haenens, Leen; Roe, Keith (2013). “Online risks: Coping strategies of less resilient children and teenagers across Europe". Journal of children and media, v. 7, n. 1, pp. 60-78.

https://doi.org/10.1080/17482798.2012.739780

Vincent, Jane; Fortunati, Leopoldina (2009). Electronic emotion: The mediation of emotion via information and communication technologies. Oxford: Peter Lang. ISBN: 9783039118663

Wachs, Sebastian; Wright, Michelle (2018). "Associations between bystanders and perpetrators of online hate: the moderating role of toxic online disinhibition". International journal of environmental research and public health, v. 15 , n. 9, 2030.

https://doi.org/10.3390/ijerph15092030 